\title{
Dramaturgia local y desplazamiento global: El Pasaje de Carlos Alsina*
}

\author{
Local dramaturgy and global displacement: \\ El Pasaje by Carlos Alsina
}

José María Risso Nieva**

\begin{abstract}
RESUMEN
Carlos Alsina desarrolla una prolífica carrera como dramaturgo en Tucumán, provincia del noroeste de Argentina y, al mismo tiempo, sostiene una fluida relación de intercambio artístico con Europa. Desde la comparatística teatral, nos interesa comprender cómo la obra $E l$ pasaje se inscribe en un proyecto dramatúrgico provincial y, a su vez, acompaña el constante desplazamiento del autor. El drama propone una recreación del mito clásico del viaje al Más Allá, que forma parte del horizonte global y, sobre este esquema, monta una crítica a la repetición, atenta a la historia de Tucumán, que inaugura la diferencia local.
\end{abstract}

\begin{abstract}
Carlos Alsina develops a prolific career as a playwright in Tucumán, province of northwestern Argentina, and, simultaneously, he maintains a fluid artistic interchange with Europe. From the comparative theater, it interests us to understand how the play El pasaje is part of a provincial dramaturgical project and, at the same time, accompanies the constant displacement by the author. The drama proposes a recreation of the classic myth of the death trip, that it is part of the global horizon, and, on this scheme, mounts a critic to the repetition, related to the history of Tucumán, that it inaugurates the local difference.
\end{abstract}

Palabras clave: dramaturgia, desplazamiento, local/global, $E l$ pasaje, Carlos Alsina.

Keywords: dramaturgy, displacement, local/global, $E l$ pasaje, Carlos Alsina.

El presente artículo forma parte del trabajo de investigación realizado por el autor en el marco de la tesis doctoral en curso denominada "La tradición clásica grecolatina y la dramaturgia contemporánea de Tucumán (1994-2015)" y de una beca otorgada por el Consejo Nacional de Investigaciones Científicas y Técnicas, Conicet.

** Argentino. Licenciado en Letras. Jefe de Trabajos Prácticos en la Universidad Nacional de Tucumán y becario doctoral del Conicet. Tucumán, Argentina. jose.risso@filo. unt.edu.ar 


\section{Introducción}

El retorno de la Argentina a la democracia en 1983 impulsó una transformación cultural a nivel nacional y Tucumán, provincia del noroeste del país, ingresa en una nueva etapa de afirmación y cambio teatral. La historiografía observa, como rasgo distintivo del periodo, una "profusión de autores locales", que escriben y estrenan en la provincia, en el marco general de una "renovación" del lenguaje escénico (Tríbulo, “Tercera parte" 117). En la configuración de esta escena, consolida su nombre Carlos Alsina, quien había dado sus primeros pasos como autor durante la transición democrática y, a partir de entonces, desarrolla una prolífica carrera como dramaturgo. Al margen de esta participación en el movimiento teatral local, desde 1990 Alsina sostiene una fluida relación de intercambio artístico con Europa - principalmente con Italia-, y reparte su producción dramática entre ambos continentes, escribiendo y dirigiendo sus obras en una y otra geografía. La pieza El pasaje constituye un ejemplo de esta capacidad para organizar el trabajo tanto en el lugar de acogida como en el de origen: primero fue estrenada en Verona (1998), luego repuesta en Roma (2001) y, finalmente, en Tucumán (2006). El pasaje propone una recreación del mito clásico sobre el viaje al Más Allá y organiza la disposición dramática alrededor de la antítesis vida/muerte. Nos interesa comprender cómo la obra, sostenida en la recepción del imaginario grecolatino antiguo, responde a un proyecto dramatúrgico local y, a su vez, acompaña el constante desplazamiento global del autor ${ }^{1}$.

\section{La perspectiva teórica y disciplinar}

Concebimos, en términos generales, la praxis dramatúrgica como la "organización de la acción en función de la escena" (Danan 50, cursivas del original), tarea que despliega "la acción, ordena un espacio y una temporalidad, e inventa personajes" (Danan 50) para la visión del espectador. En el caso particular de Alsina, esta disposición queda de-

1 Tanto la pieza que seleccionamos como el problema del desplazamiento han recibido escasa o nula atención en el corpus crítico generado alrededor de la obra de Alsina, que ha prestado atención a otras piezas de su producción y se ha interesado por otros tópicos, entre ellos: la dimensión política, el trabajo con la memoria o la recuperación de la historia, la mitología y la cultura de Tucumán en su dramaturgia (Diago párr. 8-12; Dubatti, "El teatro..." 7-10; García y Mozzoni 55-63; Tossi, "Discursos de alteridad..." 137165; “Discursos identitarios..." 5-27; “Emergentes..." 479-481; Tríbulo, "El mito..." 80-82). 
finida fundamentalmente por su trabajo como autor, que elabora una "obra dramática", como "codificación literaria" a priori de un espectáculo (García Barrientos 33) y, en menor medida, por su posterior labor como director, que determina el rumbo de la escenificación como producto final.

Entendido como un acontecimiento "convivial”, basado en la conjunción de presencias, el teatro se inscribe necesariamente en coordenadas espaciales y temporales concretas, es decir, en un "centro territorial" (Dubatti, El convivio... 17). De acuerdo con esto, nuestra investigación se ubica en el ámbito de la comparatística teatral, como disciplina que aborda "los fenómenos teatrales considerados en su territorialidad - por relación o contraste con otros fenómenos teatrales territoriales" (Dubatti, Introducción... 115-116). La "territorialidad" implica el abordaje del "teatro en contextos geográficos-históricosculturales singulares" (Dubatti, Introducción... 116) y la comparatística surge a partir de su problematización. En este sentido, el drama que consideramos pone en tensión los vínculos topográficos (la obra se estrena sucesivamente en contextos geográficos diversos: Verona, Roma y Tucumán) y diacrónicos (un tema antiguo, como el mito del viaje al inframundo, es recreado por el teatro contemporáneo).

El pasaje, en el marco de un proyecto dramatúrgico local concebido por Alsina desde Tucumán, funciona en medio de un complejo intercambio internacional y, a su vez, recupera el repertorio cultural clásico que - en las nuevas condiciones del orden mundial — forma parte de un "horizonte global” (Settis 13). ¿Cuál es, entonces, el sentido de lugar que consigue inaugurar la obra frente a la homogeneidad temática y el desplazamiento territorial que se imponen?

\section{El relato de viaje}

Carlos Alsina escribe y estrena la obra El pasaje en Italia. La escritura está situada en "Verona, Octubre de 1997" (Alsina, "El pasaje" 59) y el estreno tiene lugar el 30 de enero de 1998, en el Teatro Santissima Trinità de dicha ciudad. Luego, en el mismo país, la pieza registra una nueva escenificación el 3 de abril de 2001, en el Teatro dell'Orologio de Roma. Finalmente, tras esta travesía por Europa, la puesta del texto en Tucumán acontece el 29 de junio de 2006, en el Teatro El Pulmón. En todos los casos, la dirección del espectáculo estuvo a cargo del autor. 
El pasaje constituye un ejemplo de esta producción textual, inmersa en un constante movimiento cultural, que define la labor de Alsina y que puede pensarse a partir de la dinámica migratoria. El autor, a lo largo del tiempo y en múltiples ocasiones, ha discurrido acerca de este desplazamiento y configura, con cada declaración, una suerte de "relato de viaje". Esta narración, que podemos reconstruir a partir de los dichos del autor, contiene la estructura básica de la travesía: partir, viajar, volver (Nucera 247).

El relato, en un primer momento, identifica como "lugar de origen" a Tucumán, espacio vital vinculado con el nacimiento, la infancia, la escolarización y el inicio de una carrera profesional en el campo escénico local, como actor, dramaturgo y gestor cultural:

Nací el 12 de septiembre de 1958. Viví hasta los 31 años en Tucumán. (...) Hice toda mi niñez en esta provincia. (...) [M]e inscribí en los talleres teatrales del grupo Nuestro Teatro (...). A partir del primer año de trabajo me invitaron a participar del montaje de Los Prójimos de Carlos Gorostiza (...). De este modo me incorporo a Nuestro Teatro, sigo participando de otras puestas hasta que con algunos compañeros del taller decidimos construir nuestro propio grupo, aproximadamente en los años 80, 81. Así surge el grupo Teatro de Hoy. (...) Entonces, el 1 de abril de 1982, (...) estrenamos en la Sala Metropol dos textos breves: uno, de G. Geirola que se llama El paraíso de las hormigas; y otro de mi autoría, el título es Contrapunto. (...) [En esos años también] fui secretario gremial de la Asociación Argentina Actores. (Alsina, "El teatro como arqueología..." 29-30)

El momento de la partida que inicia la migración, está determinado por el proceso hiperinflacionario que, a partir de 1989, apremiaba la situación económica de la Argentina:

En esa situación crítica que vivía el país (...), decido probar suerte en Europa. ¿Por qué Italia, país que no conocía aún? Porque mi compañera de entonces, que tenía un hijo pequeño, podía adquirir la ciudadanía italiana (...) y en segundo lugar porque yo me había fascinado por el teatro de Dario Fo. Como había hecho dos obras suyas y le había pedido los derechos para representarlas tenía cierto contacto epistolar con él y su agente. Entonces le escribí una car- 
ta contándole la desesperante situación en la que me encontraba con mi familia y pidiéndole simplemente que me dejase asistir a los ensayos de la nueva obra que estaba preparando. Nada más. Fo, gentilmente, me contestó que sí, y es así que vendemos todo, (...) y nos embarcamos para Milán. Desesperación, inconciencia, fascinación por la aventura también. (Alsina, "Hacer teatro hoy..." párr. 11)

A partir de 1990, Alsina fija residencia en Europa e Italia figura como el "lugar de acogida", donde el artista permanece y trabaja por un lapso de cuatro años. Luego, en la reconstrucción de este relato, la travesía del dramaturgo completa el esquema del viaje con el "retorno" al origen, que jamás resultará definitivo, sino que por el contrario, promoverá siempre una nueva partida, en un ciclo de intercambios culturales ininterrumpido. Como refiere Alsina en 1998 a la prensa local, con motivo del estreno de El pasaje en Verona: "estoy yendo y viniendo desde el año 90. Primero viví casi cuatro años y luego comencé a viajar cada dos o tres meses, depende de los trabajos que tengo. También hago algo en Tucumán" ("Carlos Alsina, en un continuo" s/p).

El artista, a pesar de este nomadismo cultural, interviene activamente en el campo teatral de Tucumán como director, gestor y docente y, en especial, su dramaturgia moviliza la productividad del medio. Desde el primer retorno, en 1994, y hasta 2019 (la pandemia por COVID-19 detuvo el desarrollo de la actividad teatral en 2020 e impidió el retorno de Carlos Alsina a la provincia), registramos en su actuación local trabajos como director, llevando a escena textos ajenos y propios. Desarrolla también un rol en el medio como gestor cultural, dentro del que cabe destacar la dirección artística del Teatro Alberdi, dependiente de la Universidad Nacional de Tucumán, durante el periodo 20002003, y del Teatro El Pulmón, espacio independiente creado y administrado por Alsina a partir de 2002. A esta labor se suma su trabajo como docente a través de la organización de cursos, seminarios y conferencias. Como dramaturgo, el autor ha estrenado varios textos de su producción en el contexto provincial y su nombre figura regularmente en la cartelera local con títulos como: El sueño inmóvil (1995), La guerra de la basura (1999), Los pedidos del viejo Miseria (2000), Desde el andamio (2004), Por las hendijas del viento (2005), La conspiración de los verdaderos dioses (2006), Marx contraataca (2009), Ceguera de luz 
(2010), Dakar Eslovenia Tucumán (2011), Acomodarse (2013), Supelmelcado La Otla Patlia (2014), Artigas, el relámpago encerrado (2015), El discreto encanto de la compra venta (2017) y Las manos del tiempo (2018).

En el marco de este desplazamiento constante entre Italia y Argentina, Carlos Alsina, opera como un "mediador cultural" entre "la cultura del país de origen y la del país de acogida" (Ruiz Sánchez 107). Escribe, dirige y estrena sus textos en una y otra geografía, se ocupa de la traducción lingüística, convoca a actores y arma elencos en cada lugar y aparece regularmente en los medios de comunicación. Según esta lógica, los "[d]estinatarios de su trabajo son los pertenecientes a ambas comunidades nacionales" (Ruiz Sánchez 107). La obra El pasaje ejemplifica esta capacidad para organizar el trabajo tanto en el lugar de acogida como en el de origen. Alsina funda en 1997, en Verona, el grupo teatral "Trixtragos", con un conjunto de actores que había asistido a sus clases de actuación. El autor escribe especialmente para esta agrupación el texto El pasaje. Como la lengua de creación es el español, Alsina convierte el texto al italiano, con la ayuda del actor Marco Cantieri, y lleva a escena la traducción en 1998 (Alsina, entrevista personal, 11 de julio de 2017)2. Posteriormente, Alsina reestrena esta versión en Roma (2001) y el texto original en lengua española en Tucumán (2006), siempre a cargo de la dirección y al frente de un elenco distinto. Cada una de las puestas obtiene cobertura mediática y crítica, ya sea en el lugar de acogida o en el lugar de origen.

Corresponde señalar cómo, en el marco de esta visibilización del trabajo, la prensa representa a Alsina como una figura migrante, enfatizando — según el caso- su ajenidad o su ausencia. En relación con El pasaje, por ejemplo, la prensa italiana, en el momento de cubrir el estreno u ofrecer una crítica, tiende a señalar constantemente la extranjería del autor de la pieza, haciendo hincapié en su nacionalidad: "Carlos Alsina, drammaturgo e regista argentino"3 ("Signora e marinaio" s/p), "Scritto e diretto dal drammaturgo e regista argentino

2 Entrevista personal a Carlos Alsina. Entrevistador: José María Risso Nieva. La entrevista se realizó el día 11 de julio de 2017 en el Teatro El Pulmón (Córdoba 86), San Miguel de Tucumán, Tucumán, Argentina

3 "Carlos Alsina, dramaturgo y director argentino" (la traducción es nuestra). 
Carlos Maria Alsina"4, "Alsina (...) nel suo Paese ha ottenuto diversi riconoscimenti per l'impegno civile dei suoi lavori" ("Tre personaggi" párr. 1). Por su parte, los diarios de Tucumán, al referir los estrenos extranjeros de 1998 o 2001, inscriben (y reclaman) al autor (y al texto) en el lugar de origen, en virtud de la pertenencia territorial, la lengua de creación y una esperada actuación en el campo: "La obra fue escrita en español cuando Alsina estaba en Verona, aunque se representa en italiano", "no fue aún estrenada en Tucumán”, “[Alsina] confesó su interés de realizarla también en Tucumán" ("Un tucumano" 3).

Carlos Alsina, aunque a veces escriba y estrene en el extranjero como consecuencia de su condición migrante, busca reafirmar el sentido de lugar y definir "las condiciones de identificación y reconocimiento" (Bessière 19) de su dramaturgia:

(...) más allá del lugar en donde uno esté produciendo -y esto es una constante en muchos escritores- verdaderamente se ve mucho más claro tu lugar desde lejos. Siempre he hablado de la Argentina desde la distancia. Si hay una influencia europea en mi obra es el poder reconocer mi lugar, mis pertenencias, las diferencias entre un primer mundo y un tercer mundo más allá de solo presunciones, reconocer nuestras potencialidades y debilidades, así como también, nuestro dolor. (Alsina, "El teatro como arqueología...” 39)

El autor, como sujeto consciente a través de un "lugar", que en la cita precedente está enunciado como "Argentina", concibe -en otras declaraciones- una pertenencia geográfica-histórica-cultural compleja, a partir de la interacción de distintas escalas espaciales: "Yo me reconozco como una persona de América Latina, de Argentina, de Tucumán, más allá de que puedo renegar o no. Por lo tanto, mi origen esta acá" (Alsina, entrevista personal, 11 de julio de 2017). Este compromiso entre lo subcontinental, lo nacional y lo local imagina un centro territorial en la periferia del mundo, para configurar una nueva cartografía cultural que cuestiona la autoridad o el predominio de las

4 "Escrita y dirigida por el dramaturgo y director argentino Carlos María Alsina" (la traducción es nuestra).

5 "Alsina (...) en su país ha obtenido varios premios por el compromiso cívico de sus obras" (la traducción es nuestra). 
metrópolis, tanto en el orden internacional (primer mundo versus tercer mundo) como en el nacional (capital versus interior).

Carlos Alsina, en relación con su trayectoria migrante, busca fijar un lugar de enunciación y, a su vez, autorizar un contexto de interpretación para su obra: "elijo expresarme de este modo, elijo mi lugar periférico y desde allí lanzarme al exterior" (Alsina, "El teatro como arqueología..." 38). Su producción textual, a pesar de la diáspora, integra la historia dramatúrgica local, organizada alrededor de "un movimiento de autores que escriben desde Tucumán y representan conflictos humanos que los sensibilizan de este lugar, del país y del mundo" (Alsina, "La dramaturgia en Tucumán" párr. 8).

\section{El manifiesto caníbal}

El "dramaturgo de la periferia" enfrenta un desafío cultural singular: "la defensa de una identidad, identidad puesta hoy en duda, confrontada con una lucha de culturas" (Alsina, "El teatro como arqueología..." 38). Este proyecto supone la necesidad de construir un espacio de "resistencia" frente a la centralización, por parte del puerto de Buenos Aires (Alsina, "La dramaturgia de la periferia" párr. 13), y a la homogeneización cultural, como estrategia del colonialismo global (Alsina, Teatro, ética y política... 178). Esta misión que asigna Alsina al autor teatral local está vinculada con su posición política como "hombre de izquierda" (Alsina, "El teatro como arqueología...” 38) y determinada por una concepción de mundo y una idea de cultura:

(...) el desarrollo mundial del capitalismo, en su etapa globalizadora, tiende a unificar los hábitos, gustos e identidades nacionales con el objetivo de ampliar el mercado cultural (vender más) y 'conquistar las cabezas' de quienes vivimos en regiones del mundo sometidas a su poder económico (o militar). (Alsina, Teatro, ética y política... 178)

Asimismo, este compromiso con la periferia asume una revisión hacia el interior de la práctica artística. Como señala Alsina, el arte se ejercita "continuando" aquello que lo precede (Teatro, ética y política... 178), en la medida que cualquier creador enfrenta la acumulación de experiencias artísticas pretéritas. Sin embargo, esta continuidad inevitable entre presente/pasado también involucra, en el proceso, la "ne- 
gación" (Teatro, ética y política... 178). La dramaturgia, como práctica escénica, frente a esta mirada sobre el mundo, por un lado debe evitar la unificación cultural y, por otro, inscribir el trabajo en la continuidad por la vía negativa, es decir, con deliberada intención transformadora. Estas premisas, que definen el compromiso del arte, atienden a dos procesos que concebimos de forma estrechamente relacionada: hacer propio lo ajeno (apropiación) e inscribir el pasado en el presente (actualización). La problemática de la homogeneización y la conservación cultural adquiere en Alsina una dimensión política fundamental: el artista, aunque puede acomodarse y complacer al poder instituido y al pasado heredado, debe resistir y cuestionar el presente y lo dado. Esta óptica suscita en torno a la labor dramática una serie de interrogantes, que el autor ejemplifica a partir de la obra de William Shakespeare, concebida como un corpus textual ajeno y antiguo y que, en virtud de nuestro interés, podemos homologar a la recepción del pasado clásico:

¿Cómo resistimos? ¿Oponiéndonos a todo lo que es extranjero solo por el mero hecho de serlo? ¿No representaríamos, entonces, a Shakespeare (...)? Sería absurdo. Creemos que el modo es 'fagocitar' a Shakespeare poniéndolo en escena a través del filtro crítico de nuestra realidad (...) y encontrando el modo expresivo propio que, inevitablemente será cuestionador del modelo o cliché predominante. (Teatro, ética y política... 178)

Como se desprende de la cita, Alsina pretende desestabilizar la habitual oposición entre lo nacional y lo extranjero, lo interno y lo externo, el adentro y el afuera, lo viejo y lo nuevo, imponiendo en el debate una nueva dicotomía: acrítico/crítico ("La dramaturgia de la periferia" párr. 34-35). Ser crítico, en el marco de este proyecto, implica comprometer el lugar de enunciación, hic et nunc, en favor de una creación artística situada. El teatro entonces no es reducido a un fenómeno de comunicación o entretenimiento, sino que es concebido fundamentalmente como un espacio de resistencia simbólica, que debe "cuestionar" al poder dominante, "desde un lugar 'periférico' (...) y con una actitud 'crítica”' (Alsina, "La dramaturgia de la periferia” párr. 33).

Carlos Alsina, en este desarrollo, retoma explícitamente el "canibalismo" del emblemático "Manifiesto Antropófago" de Oswald de Andrade (Brasil, 1928). La fagocitación, como tropo cultural, es entendida por Alsina como el acto de 'comer' lo que viene de afuera y hacer la 
propia digestión; descartar lo que nos sirve de lo que no" "La dramaturgia de la periferia" párr. 36). La perspectiva abierta por Andrade, a través de la antropofagia, como metáfora de constitución/disolución de identidades, imagina una manera tanto de apropiación de lo foráneo como de actualización del pasado:

(...) no involucra una sumisión (...), sino una 'transvaloración': una visión crítica de la Historia como función negativa (...), capaz tanto de apropiación como de expropiación, desjerarquización, deconstrucción. Todo pasado nos es 'otro', merece ser negado. Vale decir: merece ser comido, devorado. (De Campos, citado en Franco Carvalhal 107)

Oswald de Andrade, "[e]n lugar de rechazar la cultura y las tendencias artísticas europeas por extrañas, (...) proponía devorarlas, aventurando una exitosa correspondencia analógica entre el rito caníbal y los diversos procesos de apropiación, circulación y producción culturales" (Jauregui 47). La resignificación de esta propuesta, para imaginar el desarrollo local, le permite a Carlos Alsina, por un lado, cuestionar prácticas extremas como el "cholulismo" o el "chauvinismo", que imponen la idea de que es mejor todo lo que viene de afuera o de adentro, respectivamente y, por otro, superar aquellas prácticas artísticas que él denomina "museísticas" o "vanguardistas" y que asignan un valor estético a priori a lo pretérito o a lo nuevo, en uno u otro caso (Alsina, "La dramaturgia en Tucumán" párr. 16-18; Teatro, ética y política... 109-110; entrevista personal, 11 de julio de 2017).

Carlos Alsina concibe la fagocitación como una estrategia cultural consciente para invertir el signo de la colonialidad capitalista y rebelarse contra el poder opresor:

(...) como pueblos dominados y más jóvenes, podemos aprovechar los adelantos de las culturas dominantes y darles nuestra propia dirección cuando nos demos cuenta de la necesidad de crear y construir nuestro propio modelo, quizás como síntesis independiente en un mundo globalizado del cual sería imposible e inútil aislarse. (Alsina, “La literatura teatral..." 165-166)

$\mathrm{Al}$ respecto, la crítica vinculada a la propuesta de Andrade señala: "Ahora es el representante de la cultura periférica y dependiente que ataca la del colonizador, mutilándola, exprimiéndole el jugo para ex- 
traer de ella solamente lo que le (...) conviene" (Franco Carvalhal 108). El tropo digestivo, en el caso de Alsina, funcionaría entonces como un dispositivo de autorización estética y cultural frente a las metrópolis y como mecanismo simbólico diferencial de participación en el orden global. Para el dramaturgo de la periferia, instalado en la posición antropofágica, cualquier material puede ser retomado en el proceso creativo e implicado en la elaboración de una imagen del presente, capaz de develar conflictos personales o colectivos: "nuestros creadores deberían 'fagocitar' todo lo que les llega desde el exterior o desde el interior, hacer su propia 'digestión' y esa síntesis será su creación más auténtica" (Alsina, Teatro, ética y política... 139).

En la dramaturgia de Alsina, el acto de representar el lugar de origen atravesado por este apetito caníbal, admite una diversidad de selecciones y combinaciones morfológicas y temáticas que configura un corpus textual heterogéneo. Aunque el autor no descarta cierta acentuación regionalista, recurriendo a los temas o la lengua del terruño, no circunscribe su proyecto dentro de los límites de esta poética. Al respecto, Dubatti divide la producción dramática de Alsina en dos grupos: una "primera serie de obras, estrechamente condicionada por la realidad regional de Tucumán y el noroeste argentino" y una segunda, marcada por "un alejamiento de la problemática localista estrictamente tucumana" ("El teatro de Carlos Alsina..." 7-8). La obra El pasaje, por ejemplo, pertenece a esta segunda línea poética, en la medida que el posible vínculo inicial con el lugar de origen es sometido a una compleja estructuración y el texto queda desprovisto de marcas explícitas que reenvíen al referente local. No obstante, como veremos más adelante, esta pretendida "lugarización" puede ser reconocida al incluir la pieza en el conjunto macropoético organizado alrededor del exceso trágico de la repetición.

\section{El mito del viaje al Más Allá}

A diferencia de otros dramas de Alsina, como por ejemplo Limpieza (1988), El sueño inmóvil (1997), La guerra de la basura (1999), Por las hendijas del viento (2008), Dakar Eslovenia Tucumán (2011) o Supelmelcado La Otla Patlia (2014), que recuperan la historia o la mitología del noroeste argentino, El pasaje carece de este tipo de alusiones y propone una recreación del mito clásico sobre el viaje al Más Allá, 
en el cual resulta una figura fundamental el barquero Caronte, como divinidad encargada de trasladar las almas de los muertos, a través del río Aqueronte, hasta su destino final: el Hades. La travesía opera en una frontera, tanto física como existencial que, por un lado, separa una orilla de la otra y, a su vez, divide el cosmos de la vida y de la muerte.

La inscripción de la pieza en la tradición clásica grecolatina queda establecida de manera explícita a través de una serie de documentos que organizan los alrededores del espectáculo. En relación con el estreno de 2006, la primera referencia - que promueve una lectura de tipo hipertextual-, está contenida en el programa de mano:

"El pasaje" es una metáfora sobre la fugacidad de la existencia (...). Se ha tomado para ello, como punto de partida, un antiguo mito. Tres personajes navegan sobre una balsa y cruzan un misterioso río. Dos de ellos, el remero y la enfermera, transportan a la señora hacia la otra orilla.

Este indicio, a su vez, tiene como complemento las declaraciones del dramaturgo y director brindadas a la prensa local con motivo de la puesta escénica del texto acontecida en Tucumán: “La obra (...) remite en ciertos puntos al personaje griego de Caronte, que conducía en su barca las almas de los muertos al otro lado del Hades" ("Tres personas" párr. 2).

Bajo esta consideración, ¿qué dimensiones del antiguo mito del viaje al Más Allá conserva y transforma el drama El pasaje? En primer lugar, corresponde señalar que la dramaturgia cuestiona deliberadamente la disposición temática habitual: en lugar de operar por acumulación de certezas, la organización de la acción trabaja deliberadamente para erosionarlas. Esta premisa que busca "romper" la progresión y, por lo tanto, evitar una exposición lineal de la acción, contraviene los principios de la forma dramática "cerrada", que "tiene su origen en la doctrina aristotélica, particularmente en las exigencias de unidad e integridad" (García Barrientos 77). Frente a la tendencia a la concentración informativa de la forma cerrada, la estructura de El pasaje intenta provocar en el espectador una sensación constante de incertidumbre $o$ desconcierto acerca de lo que está viendo. En virtud de esta búsqueda, la perspectiva cognitiva del drama, es decir, el grado de conocimiento que comparten los personajes y el público, se inclina por el "extraña- 
miento", en la medida que el espectador sabe menos que las personas del drama y siente la carencia de la información (García Barrientos 220-221). Esta falta será parcialmente compensada en el cuadro final o epílogo de la obra. Como señala Alsina, el acto de fagocitar compromete tanto "la historia que armás o representás, como (...) el modo de hacerlo" ("El teatro como arqueología..." 38). Por lo tanto, esta propuesta expresiva debe considerarse como una estrategia de resistencia, en la medida en que rompe deliberadamente con la estructura formal aristotélica, para cuestionar un hábito arraigado en la visión del espectador y jerarquizar el trabajo del público en la producción del sentido ("El teatro como arqueología..." 36). La disposición dramática abierta obliga al espectador a entramar los hechos de la escena para dotarlos de un sentido, que resultará auténtico y personal y que no está direccionado por las fórmulas de la disposición dramática cerrada. La recuperación y transformación del hipotexto clásico debe comprenderse, entonces, en el marco de este planteo expresivo.

En principio, la fábula de El pasaje está montada — siguiendo la acción mítica - sobre el motivo del viaje: tres personajes, a bordo de una balsa, cruzan un río. En esta travesía, la Señora es acompañada por la Enfermera y el Remero. Aquí puede reconocerse una primera instancia de apropiación del legado clásico, en la medida que el mito de Caronte propone un idéntico esquema: el paso de una orilla a otra. El río representa, en principio, un obstáculo geográfico que debe ser físicamente traspasado. A partir de este motivo, que instala cierta linealidad, la disposición configura un conflicto de poder, puesto que la Señora condiciona el campo de acción de sus acompañantes. La fémina puede intervenir en la conducta de sus compañeros en virtud del dinero que posee. Su riqueza le permite contratar al Remero y a la Enfermera e iniciar la travesía. En función de este poder, los acompañantes están obligados a satisfacer los deseos de la Señora y a obedecer sus órdenes. En principio, la Enfermera y el Remero deben cumplir con las funciones para las cuales han sido empleados: cuidar la salud de la mujer y conducir la barca, respectivamente. No obstante, ambos tienen que responder también a los apetitos sexuales de su empleadora. Este deseo inaugura un segundo conflicto, de tipo erótico, en la medida que las figuras femeninas compiten por la posesión física y sentimental del barquero. El drama construye esta tensión en un segundo nivel o ins- 
tancia metateatral, que responde a la fórmula "teatro dentro del teatro" (García Barrientos 232), en la medida en que no representa una lucha auténtica entre los personajes, sino una falseada. Los personajes no se enfrentan en función de intereses contrapuestos, sino en virtud de una necesidad de la Señora. En el devenir de la acción, queda sugerido que la instauración de esta rivalidad, en torno al varón, replica situaciones experimentadas anteriormente entre la mujer y su marido. Este hombre, ausente en el drama, le ha sido infiel en numerosas ocasiones y este es un trauma que la Señora intenta resolver y, para ello, ubica al Remero en el rol del esposo y a la Enfermera, en el de la amante. La presentación de estas situaciones "teatralizadas" contribuye a la generación de la incertidumbre, como premisa de creación dramática, en tanto duplica los niveles de ficción.

Por su parte, frente a esta imposición, los acompañantes detentan un poder alternativo, vinculado con la posesión de un saber específico. Son los conocedores de la ruta y este dominio les permite incidir en las decisiones de la Señora. Existe entre ellos una complicidad que se manifiesta a través de un constante juego de miradas. Cuando, por ejemplo, la mujer les ordena regresar, la Enfermera y el Remero - basándose en su ignorancia - fingen retroceder, pero en realidad avanzan hacia un destino fijado de antemano: "EL REMERO (...) parece que rema en la dirección contraria. En realidad, sin ser visto por LA SEÑO$R A$, rema en la misma dirección que antes" (Alsina, "El pasaje" 40, cursivas y mayúsculas del original).

Como hemos señalado, al igual que en el hipotexto clásico, los personajes a bordo de una balsa atraviesan un río. La dramaturgia resuelve la representación del espacio visible de dos modos, a saber:

a) una disposición escenográfica "estilizada" (García Barrientos 145) que, según los documentos visuales conservados, emplea una tarima, a modo de balsa, un baúl, una silla y un remo, privados de marcas distintivas o detalles naturalistas que remitan a una época o lugar específicos (Ver Figuras 1 y 2).

b) el "decorado verbal", que usa la palabra para significar el río de manera "convencional" (García Barrientos 146). Empleando esta técnica, los personajes representan el agua como espacio inmediato. A lo largo de la acción y a través de los diálogos, los tripulantes de la 
barca proporcionan datos sobre el lugar, describiendo el estado del río o el paisaje circundante: "Hay corriente. (...) Hay bruma” (Alsina, "El pasaje" 20).

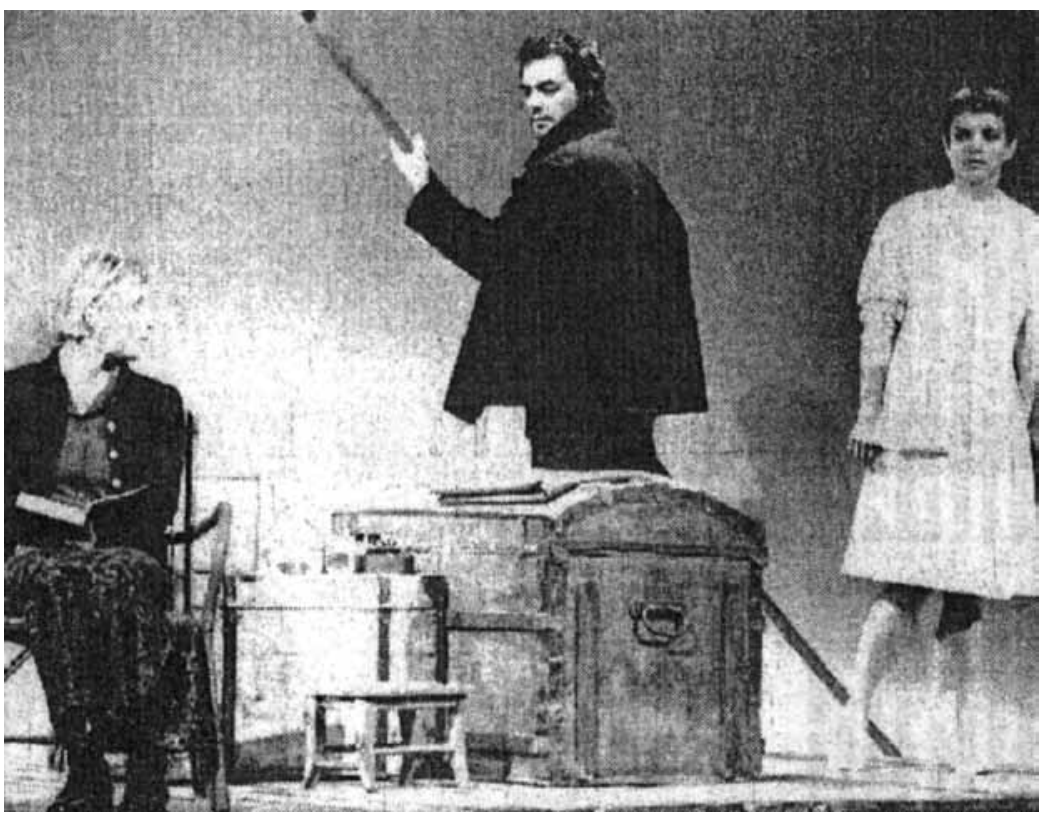

Figura 1. El pasaje (Verona, 1998) (“Il mistero" 38).

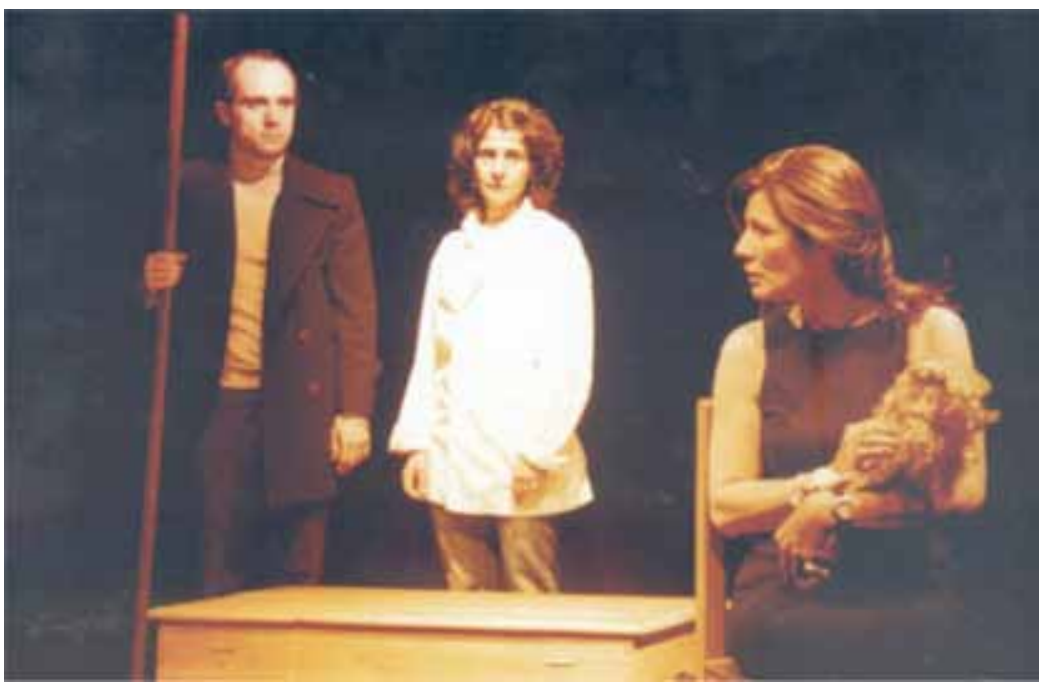

Figura 2. El pasaje (Tucumán, 2006) (“Tres personas” s/p). 
Sin embargo, a diferencia del mito, donde las referencias de salida y arribo son claras (una y otra orilla del río Aqueronte), en la obra estas coordenadas son escamoteadas al conocimiento del espectador. En el transcurso del drama, el destino de la travesía permanece en una constante indeterminación. Existe en los personajes una certeza del objetivo, "llegar", pero no realizan ningún tipo de precisión en cuanto al lugar de acogida. De acuerdo con ello, la obra deja sin caracterizar los espacios latentes, es decir, aquellos sitios que continúan "más allá de los límites del espacio escenográfico" (García Barrientos 137). Entonces, la única certeza al respecto resulta ser el "pasaje”. Con la representación del tiempo sucede lo mismo, puesto que no existen referencias claras respecto del período que llevan navegando ni el que aún les falta transitar. La única referencia temporal clara es el presente, un "hoy", recortado del pasado y del futuro.

En relación con los personajes, en principio, debemos señalar que la acción está sostenida por entidades anónimas, identificadas según el rol (la Señora, la Enfermera, el Remero) y desprovistas de referencia geográfica, histórica y cultural precisa. La dramaturgia, en este aspecto, opera con personajes elaborados como "tipos" y reducidos a una actividad. Como explica Pavis: "Hay creación de un tipo a partir del momento en que las características individuales y originales son sacrificadas en beneficio de una generalización y de una ampliación" (481). En relación con lo expuesto, la transformación de Caronte como única figura con nombre del mito, en el Remero, como personaje-tipo, constituye un caso de transposición semántica diegética (Genette 379), que opera por la vía negativa, anulando la marca de identidad, sin sustituirla por otra. Podemos reconocer la equivalencia fundamentalmente alrededor de la tarea: ambos son los conductores de la balsa y los conocedores de la ruta. Como ha señalado la crítica especializada, es en la misión y no en el nombre donde se juega la singularidad del hipotexto: Caronte no representa un modelo heroico sino solo una función, un cometido que se restringe a navegar por el camino de la muerte (Diez de Velasco 42-43).

A su vez, en El pasaje, queda inicialmente sugerido que, al igual que la divinidad mítica, el Remero persigue un interés material: el dinero que la señora le ofrece como pago por sus servicios. Sin embargo, el barquero - según devela el "epílogo" o cuadro final de la obra- du- 
rante el transcurso de la acción ha fingido esta ambición solo para congraciar a la mujer. El trabajo del Remero, y también el de la Enfermera, consiste en "satisfacer los deseos imposibles" (Alsina, "El pasaje" 59) de todo aquel que cruza las aguas. En este punto, la apropiación actualiza, en la labor de estos personajes, la función atenuadora que tenían los psicopompos, como Caronte, en el camino de la muerte. Para la imaginación antigua, el tránsito al Más Allá, en la medida que estaba guiado por una divinidad, resultaba menos angustioso (Diez de Velasco 42-43).

En relación con los pasajeros que puede trasladar Caronte, el universo mítico antiguo distingue dos tipos de viajes: a) la travesía heroica, protagonizada por el héroe, que llega al Hades y luego retorna al mundo de los vivos, y b) el paso post mortem, realizado por el alma del difunto, sin retorno, con destino perpetuo en el inframundo (López de Monteagudo 40). En El pasaje, la composición de la Señora logra actualizar ambas posibilidades del viaje mítico: la mujer, siendo el único pasajero a bordo, emprende la travesía en vida, pero asume el lugar de llegada como residencia permanente, de igual modo que las almas.

El personaje de la Enfermera, aunque sin correspondencia directa en el esquema del mito, interviene necesariamente en la construcción del conflicto erótico (triángulo amoroso) y responde a una necesidad de la acción (cuidar a la mujer).

En la obra el tema de la muerte adquiere un tratamiento difuso. El episodio más claro donde el tópico es abordado resulta luego de un desmayo de la Señora, cuya absoluta inmovilidad suscita el pánico entre los tripulantes y el Remero invalida, con énfasis, la posibilidad del acontecimiento: “¡No puede ser aquí!” (Alsina, "El pasaje” 36). Esto sugiere que la defunción está prohibida en medio de la travesía y que, por lo tanto, debe suceder una vez finalizada. Asimismo, durante la teatralización de una escena, donde la mujer finge ser otra persona y habla de sus objetos como si fueran ajenos, tras preguntar por el destino final del propietario, la Enfermera describe un final pacífico: "[Murió] Con una sonrisa. Sin dolores" (Alsina, "El pasaje" 49). Se plantea aquí un tránsito hacia la muerte, sin agonía y con belleza, sostenido por el Remero como guía y la Enfermera como terapeuta. La muerte constituye el fin del viaje, puesto que en el mismo instante en que los tripulantes anuncian la llegada, la Señora pierde movilidad y, en el siguiente cua- 
dro, desaparece: "Dulcemente va cerrando los ojos y (...) Queda inmóvil" (Alsina, "El pasaje” 57, cursivas del original).

Carlos Alsina usa el mito, por un lado, como metáfora de paso, para abordar la antítesis existencial vida/muerte, por fuera del imaginario bíblico cristiano, que premia con el Cielo o castiga con el Infierno (Velasco López 32). Lejos de construir certezas alrededor de la muerte, la obra instala una interrogación respecto de la vida, bajo la consciencia de una finitud inexorable. Por otro, el antiguo esquema clásico, que presenta el viaje de una orilla a la otra, interviene en la construcción de un "pacto implícito" con el espectador, es decir, contribuye a garantizar la comunicación. En palabras del autor:

Toda obra de teatro para comunicar tiene que tener un pacto implícito con el público, en el sentido que es un pacto no dicho, pero es algo conocido por ambas partes, tanto para quienes hacen el espectáculo como para quienes lo ven; hay algo en común que nos tiene que unir. Si ese pacto implícito no está, la obra se ve incomprendida. (Alsina, entrevista personal, 11 de julio de 2017)

El dramaturgo entonces emplea el mito como mecanismo sugeridor de la memoria, pensando en la relación escena-espectador. Como señala Lotman, la recepción tiene naturaleza dialógica y, por lo tanto, el intercambio comunicativo es posible "por la presencia de determinada memoria común en el destinador (...) y el destinatario. La ausencia de esta condición hace indescifrable el texto" (111). En el marco de una estructuración dramática abierta, que impugna los principios de progresión y acumulación, el público puede contrarrestar la incertidumbre de El pasaje por el conocimiento previo del mito, que impone cierta linealidad a los sucesos de la escena y proporciona una situación para asignar un sentido "existencialista" al drama. El pasado clásico constituye un indicio, desde el punto de vista del espectador, para movilizar la recepción del espectáculo.

\section{Sentido local y horizonte global}

El pasaje organiza la disposición dramática alrededor de la antítesis vida/muerte, que constituye - al menos en el mundo occidental - una preocupación común. Retoma, para ello, un imaginario mítico conocido que, bajo la metáfora del viaje, sintetiza en un esquema de paso el inexorable devenir del ser humano hacia su finitud. El drama está 
sostenido por personajes-tipo y la acción transcurre en un marco espacio-temporal indefinido. Por estas características, dentro de la vasta producción de Alsina, El pasaje integra la serie caracterizada por el despojamiento deliberado de signos locales y sigue una línea estética, al decir de Nel Diago, "menos festiva, más amarga, más esencial, más profunda" (párr. 8).

Corresponde realizar, en este punto de la exposición, una consideración clave: ¿bajo qué aspectos este texto, resultante de la deglución antropofágica, contribuye a elaborar una imagen crítica del presente y del lugar de enunciación? Sin imponer o forzar el vínculo con el referente local, que en el drama está sublimado, es posible advertir esta pretendida lugarización a partir de la comparación de El pasaje con el antecedente y el consecuente dramático en la producción de Alsina, a saber: El sueño inmóvil, drama escrito en 1995 y estrenado en 1997 en Tucumán, y La guerra de la basura, producido y montado en la provincia en 1999.

La creación de El sueño inmóvil está estimulada por la delicada situación política de la época: a fines de 1995, A. Domingo Bussi, general genocida de la última dictadura militar argentina, ganaba la gobernación de Tucumán por la mayoría del voto popular. En la misma línea, la elaboración de La guerra de la basura (1999) está motivada por la amenazante continuidad de este proyecto autoritario: la postulación de Ricardo Bussi, el hijo del general, como gobernador de la provincia en 1999. Estos sucesos, tomados como signo de atraso e inmovilidad, describen una trama cultura local atada a un ciclo de sometimiento y despotismo perpetuo. En palabras de Alsina, esta suerte de eterno retorno comporta un exceso identificable con lo trágico:

Yo creo que la peor de las tragedias que vivimos nosotros como pueblo y como persona es la repetición. Es una tragedia social y personal. Una persona que no comprende por qué se equivocó está condenada a repetir el error y nosotros como pueblo hemos vivido muchas cosas (guerras, dictadura, genocidio) y no aprendemos y volvemos a cometer los mismos errores. (Alsina, entrevista personal, 11 de julio de 2017)

El sueño inmóvil (1995) y La guerra de la basura (1999), con diferentes grados de explicitación temática, alusión local y complejidad for- 
mal, elaboran una crítica al presente inmerso en la repetición (García y Mozzoni 55-63; Tossi, "Emergentes..." 479-481; Tríbulo, "El mito..." 80-82). El pasaje, en este proceso, no constituye una pieza aislada, sino que también puede leerse a partir de dicha preocupación. En la obra, la Señora emprende un viaje y en él replica incesantemente la trama de intrigas, complicidades y frustraciones que caracterizó su vida, una existencia en la que no puede cumplir sus deseos ni alcanzar la felicidad. Esta suerte de "eterno retorno" deriva de una imposibilidad de cuestionar el pasado. La fábula, a través de la representación de este conflicto de índole personal, devela las tramas de una historia, que sigue una peligrosa trayectoria circular. El sueño inmóvil (1995), El pasaje (2001) y La guerra de la basura (1999) conforman un conjunto macropoético que, en virtud de las semejanzas señaladas, responden a un constructo morfológico y temático de profundas implicaciones ideológicas que Alsina identifica como la "tragedia de la repetición" (Alsina, “El teatro como arqueología...” 35-36).

Esta recursividad que Alsina busca cuestionar a través de su dramaturgia, en la medida que atiende a la problemática histórica, social y cultural del lugar de origen, inscribe la diferencia en la producción textual. Este sentido de lugar, que el drama consigue inaugurar, sumado a la fagocitación del mito del viaje al inframundo, que forma parte del horizonte global, le permite al nuevo texto funcionar en las migrancias, estrenarse en una y otra geografía e incidir en ambos sistemas culturales. Esta dualidad vuelve a $E l$ pasaje, considerado en sus expresiones locales y en sus extensiones internacionales, particularmente apto para ser a la vez texto de "intercambio, de la homogeneización cultural y de la heterogeneización cultural" (Bessière 23). La pieza asume eficazmente esta paradoja y consigue negociar entre los polos: la globalización, como tendencia, y la localización, como resistencia.

\section{Conclusión}

Carlos Alsina, inmerso en un constante movimiento territorial, opera como un mediador cultural entre Tucumán e Italia. La obra El pasaje ejemplifica esta capacidad para escribir, dirigir y estrenar sus textos tanto en el lugar de acogida como en el de origen. En función de su condición migrante, el autor busca reafirmar el sentido de lugar y consigue definir un contexto de identificación y reconocimiento para su 
obra. Concibe una pertenencia geográfica-histórica-cultural en la periferia del mundo: Latinoamérica, Argentina, Tucumán y, a partir de este centro territorial, configura una nueva cartografía que cuestiona la autoridad de las metrópolis. Carlos Alsina se inscribe en un movimiento de autores que escriben desde Tucumán y su producción textual, a pesar de la diáspora, integra la historia dramatúrgica local. Como dramaturgo de la periferia, asume el desafío cultural de construir un espacio de resistencia frente a la homogeneización que impone el nuevo orden global.

Este compromiso con la periferia exige asimismo una revisión de la práctica teatral y un reposicionamiento de la figura del artista frente a la conservación/innovación del legado artístico. La dramaturgia, como práctica escénica comprometida, debe evitar la unificación cultural e inscribir el trabajo en la continuidad por la vía negativa, es decir, con deliberada intención crítica. Ser crítico, en el marco de este proyecto de resistencia simbólica, implica comprometer el lugar de enunciación y cuestionar el poder dominante. La antropofagia emerge en esta propuesta como una estrategia cultural para invertir el signo de la dominación y como un mecanismo de participación diferencial.

La obra El pasaje, a diferencia de otros dramas de Alsina que recuperan el pasado o la mitología del noroeste argentino, carece de este tipo de alusiones y propone una recreación del mito clásico sobre el viaje al Más Allá. El autor rescata de este imaginario antiguo, que forma parte del horizonte global, una metáfora de paso (vida/muerte) y, sobre este esquema, monta una crítica a la repetición, relacionada con la historia y la cultura de Tucumán, que inaugura la diferencia local.

\section{Referencias bibliográficas}

Alsina, Carlos. "El pasaje". Teatro. Ed. Universidad Nacional de Tucumán, Tucumán, 2001, pp. 13-59. Impreso.

"El teatro como arqueología del presente". Cuadernos de Picadero, no. 2, 2004, pp. 28-39.

“Entrevista personal". Entrevistado por José María Risso Nieva. 11 Jul. 2017. Inédito.

"Hacer teatro hoy. Identidad y distancia. Tucumán, las raíces, el teatro, los viajes, el injustificado sentido de inferioridad... Conversación con Carlos María Alsina". Revista Teatro CEL- 
CIT, no. 23, 2003. Recuperado de https://www.celcit.org.ar/ publicaciones/revista-teatro-celcit/17/23/ 17 de febrero de 2017.

"La dramaturgia de la periferia". Carlos Alsina, 2008. Recuperado de http://www.carlosalsina.com/articuloh.htm "La dramaturgia en Tucumán". Carlos Alsina, 2008. Recuperado de http://www.carlosalsina.com/articulog.htm

"La literatura teatral en el NOA. Presagios de la memoria. Una mirada limitada y fragmentada". Dirs. Liliana Massara, Alejandra Nallim y Raquel Guzmán. Literatura del noroeste argentino. Reflexiones e investigaciones, vol. III. Jujuy, Editorial de la Universidad Nacional de Jujuy, 2013, pp. 155-166. Impreso. Teatro, ética y política. Historia del teatro tucumano. El bussimo. Complicidades, silencios y resistencia, vol. I. Argus-a, 2013, http://www.argus-a.com.ar/ebook/400:teatro-etica-ypolitica-i.html

Bessière, Jean. "Literatura comparada e identificación de las diferencias literarias y culturales". Comp. Adriana Crolla. Lindes actuales de la literatura comparada. Santa $\mathrm{Fe}$, Universidad Nacional del Litoral, 2011, pp. 17-28. Impreso.

"Carlos Alsina, en un continuo viaje teatral". El Periódico, 21 Feb. 1998: s/p. Impreso.

Danan, Joseph. Qué es la dramaturgia y otros ensayos. Trad. Víctor Viviescas. Paso de Gato, 2012. Impreso.

De Andrade, Oswald. Obra escogida. Caracas, Fundación Biblioteca Ayacucho, 1981. Impreso.

Diago, Nel. "Breve aproximación al teatro de Carlos Alsina". Revista Teatro CELCIT, no. 17-18, 2001. Recuperado de https://www. celcit.org.ar/publicaciones/revista-teatro-celcit/13/17-18/ 17 de febrero de 2017.

Diez de Velasco, Francisco P. Los caminos de la muerte: religión, rito e iconografía del paso al más allá en Grecia. Valladolid, Editorial Trotta, 1995. Impreso.

Dubatti, Jorge. El convivio teatral. Teoría y práctica del teatro comparado. Atuel, 2003.

"El teatro de Carlos Alsina. Prólogo". Carlos Alsina. Teatro completo, vol. I. Buenos Aires, Torres Agüero Editor, 1996, pp. 7-10. Impreso. 
Introducción a los estudios teatrales. Buenos Aires, Atuel, 2012. Impreso.

Franco Carvalhal, Tania. Literatura comparada. Buenos Aires, Corregidor, 1996. Impreso.

García Barrientos, José Luis. Cómo se comenta una obra de teatro. Madrid, Síntesis, 2001. Impreso.

García, Cristian E. y Mozzoni, Valeria. “1999-2014 La guerra de la basura: 15 años de compromiso y memoria”. El umbral. Revista de Artes Escénicas de Tucumán, no. 2, 2014, pp. 55-63. Recuperado de https://issuu.com/iiae/docs/el_umbral_02-_revista_de_artes_esc_28 de febrero de 2016.

Genette, Gérard. Palimpsestos. La literatura en segundo grado. Trad. Celia Fernández Prieto. Madrid, Taurus, 1989. Impreso.

“Il mistero dell'ultimo 'Passaggio"'. L’Arena. 2 Feb. 1998: 38. Impreso.

Jáuregui, Carlos. Canibalia: canibalismo, antropofagia cultural y consumo en América Latina. La Habana, Editorial Casa de las Américas, 2008. Impreso.

López Monteagudo, Guadalupe. "El simbolismo de la travesía marina en algunos mitos clásicos". Latomus. Revue d'études latines, vol. 57, no. 1, 1998, pp. 38-51.

Lotman, Iuri M. La semiosfera I. Semiótica de la cultura y el texto. Valencia, Frónesis-Cátedra-Universitat de Valencia, 1996. Impreso.

Nucera, Domenico. "Los viajes y la literatura”. Comp. Armando Gnisci. Introducción a la literatura comparada. Barcelona, Crítica, 2002, pp. 241-289. Impreso.

Pavis, Patrice. Diccionario del teatro. Barcelona, Paidós, 1998. Impreso.

Ruiz Sánchez, Ana. “Desterritorialización y literatura. Literaturas de exilio y migración en la era de la globalización”. Migraciones y Exilios, no. 6, 2005, pp. 101-112.

Settis, Salvatore. El futuro de lo "clásico". Madrid, Abada, 2006. Impreso.

"Signora e marinaio, tour nel dubbio". Il Tempo, 10 Abr. 2001: s/p. Impreso.

Tossi, Mauricio. "Discursos de alteridad en la dramaturgia regional de la posdictadura argentina". Culturales, vol. 4, no. 1, 2016, pp.137-165. 
. "Discursos identitarios y reproductividad poética en la dramaturgia del Noroeste Argentino". Apuntes de Teatro, no. 134, 2011, pp. 5-27.

. 'Emergentes' de la religiosidad popular en el teatro contemporáneo del Noroeste Argentino". A Contracorriente, vol. 10, no. 1, 2012, pp. 472-497.

"Tre personaggi in un mare di domande". Tutto Teatro, 21 Abr. 2001, párr. 1. http://www.tuttoteatro.com/numeri/a2/4/a2n16oro.html

"Tres personas inician un viaje lleno de espejismos". La Gaceta, $26 \mathrm{Jul}$. 2006. https://www.lagaceta.com.ar/nota/168316/espectaculos/tres-personas-inician-viaje-lleno-espejismos.html

Tríbulo, Juan A. "El mito del eterno retorno en El sueño inmóvil de Carlos Alsina”. Teatro XXI, no. 16, 2003, pp. 80-82.

"Tercera parte: 1984-2004. Reactivación y renovación del campo teatral de Tucumán". Eds. Juan A. Tríbulo et al. Tucumán es Teatro. Tucumán, Fundación Grupo Cultural Wayra Killa-Instituto Nacional del Teatro, 2006, pp. 117-161. Impreso.

"Un tucumano triunfa en Roma". La Gaceta, 29 Abr. 2001: 3. Impreso.

Velasco López, María del H. "El viaje al otro mundo. Andanzas y travesías al más allá en las tradiciones indoeuropeas". Comps. Francisco M. Mariño y María de la O Oliva Herrer. El viaje en la literatura occidental. Valladolid, Universidad de Valladolid, 2004, pp. 9-33. Impreso. 